\title{
MATHEMATICAL CREATIVE THINKING ABILITY AND SCAFFOLDING PROCESS ACCORDING WITH LEARNING STYLES FOR PRE-SERVICE TEACHERS
}

\author{
Wahyudi \\ Universitas Kristen Satya Wacana, Indonesia, yudhi@staff.uksw.edu \\ Stefanus Budi Waluya \\ Universitas Negeri Semarang, Indonesia, s.b.waluya@mail.unnes.ac.id \\ Rochmad \\ Universitas Negeri Semarang, Indonesia,rochmad@mail.unnes.ac.id \\ Hardi Suyitno \\ Universitas Negeri Semarang, Indonesia, hardi.suyitno@mail.unnes.ac.id
}

\begin{abstract}
This study aimed to describe the ability of mathematical creative thinking and scaffolding process of pre-service teachers according to the learning styles. The participants were 50 first year pre-service primary teacher students. The research data were taken by questionnaire, test and interview. The questionnaire results to look at learning styles, test results to see the ability of mathematical creative thinking. Interviews were used to validate the results of thinking skills tests and scaffolding processes. The research design uses qualitative triangulation where the validity of data ability of creative thinking, scaffolding process seen from the result of test and interview. The first result of this study indicates that the subjects have different creative thinking abilities which were seen from his learning style. The second result shows that scaffolding according to the subject's learning styles can improve the ability of mathematical creative thinking. The scaffolding process begins with the provision of motivation, explaining, constructing the correct concept and working on the problem. The speed of the subject in receiving assistance through scaffolding takes different times. Although they have different learning styles, scaffolding process will be successful when used along with the media, either in the form of props and simulation drawings.
\end{abstract}

Keywords: Mathematical creative thinking, scaffolding, learning styles, pre-service teacher

\section{INTRODUCTION}

Creative is one of the major components in 21st century education (Mann, 2005). Therefore, the contemporary curriculum emphasizes the development of creative thinking skills for learners (Vale \& Barbosa, 2015; Sternberg, 2006). The ability to think creatively leads to the acquisition of new insights, new approaches, new perspectives, or new ways of understanding issues that include aspects of fluency, flexibility, and originality, and elaboration. The ability to think creatively grows from the creativity of learners. Therefore, creativity becomes something that needs to be developed in education.

This is similar to the results of research by Dyers et al. (2011) said that $2 / 3$ of a person's creativity ability is obtained through education, the remaining $1 / 3$ comes from one's genetics. In contrast to the ability of intelligence holds that $1 / 3$ the ability of intelligence is obtained from

Citation: Wahyudi, Waluya, S. B., Rochmad, \& Suyitno, H. (2018). Mathematical Creative Thinking Ability and Scaffolding Process According with Learning Styles for Pre-Service Teachers. Anatolian Journal of Education, 3(1), 39-50. https://doi.org/10.29333/aje.2018.314a 
education, 2/3 of the rest comes from one's genetic. That means we cannot do much to improve one's intelligence but we have many opportunities to improve his creativity. Creativity is applicable to all areas of learning including in the field of mathematics, especially the ability to think creatively. Thus the ability to think creatively in the field of mathematics needs to be developed so that learners have high creativity in solving mathematics problems. In addition, this ability becomes a benchmark of the success of learners in learning (Mairing \& Jackson, 2016).

The problem that arises is that not all mathematics learning provides opportunities for learners to improve their creative thinking ability. Often, learning is oriented on the amount of material given. It was seen from the rank of Indonesia for mathematics subjects in Programme Internationale for Student Assessment (PISA) in recent years Indonesia is still lower than other countries. Indonesia is ranked 64 out of 72 countries. The rank has improved, but still needs to be improved again. In addition to the rank in PISA, Indonesia's education rank still lags behind other countries, which is at the 57th rank of a total of 65 countries (World Education Ranking) published by the Organization for Economic Co-operation and Development (OECD).

This condition needs to be taken seriously by educators in this country. A change is necessary in aspect of learning mathematics for learners. Not just active learning, but also provides opportunities for learners to think more with contextual conditions. Several studies have shown that the application of innovative learning has not provided an opportunity for learners to develop their creative thinking skills in the field of mathematics (Sriwongchai at al., 2015). Therefore, it is required packing appropriate learning model.

To get the appropriate learning model, it is required a preliminary study to describe the ability to have mathematical creative thinking and how the process helps learners who still have difficulty in achieving such competence in the process of scaffolding. Scaffolding in the learning environment is a process of interaction involving the provision of assistance or guidance to learners by a teacher or friend to understand the knowledge or skills that cannot be achieved without any help (Anne at al., 2004; Jelfs at al., 2004). Scaffolding is a strategy that teachers can use in teaching and fostering the ability of learners (Bikmaz, 2010). In mathematics learning, scaffolding is an aid to solve problems, as well as help build concrete mathematical concepts and improve students' self-confidence (Akhtar, 2014). This support or assistance is tailored to the characteristics and changes in learners' abilities (Lajoie, 2005). Teachers should pay attention to the problems of each individual before providing scaffolding.

The success of learners in learning is influenced by several factors; both internal and external. One of the factors is learning styles. Learning styles will determine how teachers teach and decide which media to use (Nindiasari, 2016; Bire, 2014). This should be taken as a consideration when doing scaffolding. The scaffolding process can be done in groups (McNeill at al., 2006) and can be done with media tools (Lajoie, 2005; McNeill at al., 2006). There is limited use of media in the scaffolding process (Holton \& Clarke, 2006), so it needs to be well prepared according to the learning style that the learners have. With these considerations, it is required a good cooperation between learners and teachers in determining the media in scaffolding process (Holton \& Clarke, 2006).

This study will provide an overview of the descriptions of the ability of mathematical creative thinking and description of the scaffolding process for prospective students according to their learning style. Scaffolding process is intended for students whose the ability to have mathematical creative thinking is still low according to learning style. 


\section{METHODS}

\section{Participants}

The subjects were 50 first year students of Elementary School Pre-service Teacher from Faculty of Teacher Training and Education of Satya Wacana Christian University. In the meantime, the subjects were taking a Basic Mathematics Concept course. The educational backgrounds of the subject were from Senior High School and Senior Vocational School.

\section{Design of the Study}

This research was a qualitative research. The research design uses qualitative triangulation where the validity of data ability of creative thinking, scaffolding process seen from the result of test and interview. The scope of this research included the descriptions of the ability of mathematical creative thinking and scaffolding process according to the ability of mathematical creative thinking and learning styles.

\section{Instrumentation}

The research data were taken by questionnaire, test and interview. The questionnaire results to look at learning styles, test results to see the ability of mathematical creative thinking. Interviews were used to validate the results of thinking skills tests and scaffolding processes. Scaffolding process was done directly according to the problems of each student, observation of answers and interviews according to student answers until students understand the concept correctly.

The learning style indicators used was adopted a style questionnaire developed by De Porter that included visual, auditory and kinesthetic learning styles. The indicator of creative thinking ability is described in four aspects: fluency, flexibility, originality, and elaboration. The four aspects are described in the ability that must be owned by students as in Table 1 below.

Table 1

The Description of Mathematical Creative Thinking Aspects

\begin{tabular}{lll}
\hline No & $\begin{array}{l}\text { Mathematical Creative } \\
\text { Thinking Aspects }\end{array}$ & Description \\
\hline 1 & Fluency & $\begin{array}{l}\text { The ability of students to produce various answers correctly within } \\
\text { a short of time. }\end{array}$ \\
\hline 2 & Flexibility & $\begin{array}{l}\text { The ability of students to generate various ideas and approaches to } \\
\text { solve problems for each answers. }\end{array}$ \\
\hline 3 & Originality & $\begin{array}{l}\text { The ability of students to use a new, unique, or unusual strategy to } \\
\text { solve problems correctly }\end{array}$ \\
\hline & Elaboration & $\begin{array}{l}\text { The ability of the students to explain sequentially in detail and } \\
\text { coherently based on certain mathematical procedures, answers, or } \\
\text { mathematical situations. }\end{array}$ \\
\hline
\end{tabular}

\section{Data analysis}

The data was analysed using triangulation method, which is data analysis process by comparing information or data obtained through test result and interview, and scaffolding process for student with low creative thinking ability. The steps used in this study were presented as follows: 1) provide a learning styles questionnaire; 2) to provide students with a test of mathematical creative thinking ability; 3) analyse the obtained test results; 4) interviewing some students with low mathematical creative thinking ability; 5) analysing test results and interviews; 6) scaffolding process. 


\section{FINDINGS}

\section{Participants' Learning Style}

The subjects of this study were 50 pre-service teachers. Based on the result of the questionnaire, there were 8 students having visual learning style, 32 students had auditory learning style, and 10 students had kinesthetic learning style. Table 2, below, presented the detail of learning styles of research subjects. In detail can be presented in Table 2 below.

Table 2

The Learning Styles of Research Subjects

\begin{tabular}{lll}
\hline Learning Styles & Frequency & Percentage \\
\hline Visual & 8 & 16 \\
Auditory & 32 & 64 \\
Kinesthetic & 10 & 20 \\
Total & 50 & 100 \\
\hline
\end{tabular}

\section{Participants' Mathematical Creative Thinking Ability}

After students filled out the learning style questionnaires, they work on the test questions about geometry plane This test was used to review the subjects' mathematical creative ability. The result of of students' mathematical creative thinking ability can be seen in Table 3 below.

Table 3

Summary of Students' Mathematical Creative Thinking Ability

\begin{tabular}{llll}
\hline Interval & Categories & Frequency & Percentage \\
\hline$\geq 20,3$ & Very High & 0 & 0 \\
$16,2-20,2$ & High & 9 & 18 \\
$12,1-16,1$ & Medium & 18 & 36 \\
$8-12$ & Low & 23 & 46 \\
Total & & 50 & 100 \\
\hline
\end{tabular}

Table 3 showed that 9 students were in the high category, 18 students were in medium category, and 23 students were in low category. For students with high mathematical creative thinking, originality was the aspect that has not been mastered. They still use the same solving method.

Based on these results, the elementary school pre-service teacher has low mathematical creative thinking ability. The complete data of the 4 aspects of creative thinking is illustrated from Table 4 below.

Table 4

Summary of Mathematical Creative Thinking Results Based on the Aspects

\begin{tabular}{llll}
\hline No & Mathematical Creative Thinking Aspects & Average & Categories \\
\hline 1 & Fluency & 1,8 & High \\
2 & Flexibility & 1,2 & Low \\
3 & Originality & 1,2 & Low \\
4 & Elaboration & 1,8 & Medium \\
\hline
\end{tabular}

\section{Sample Participant Answers}

Students in the high category always try to give all aspects of the answers creatively, except for fluency and originality aspects. These subjects gave 4 solutions with different strategies. They gave successive steps to solve the problems clearly, but the strategies that they offered have not yet original because some of them are still the same as other subjects in the solution 1,3, and 4. Students with average category also have done the four aspects of thinking. The aspect which is not optimally done 
Students with average category. To give an illustration on the high category subject's work, the following shows one which has not indicated original answer but only gave one or two solutions and strategies. The following is the example.

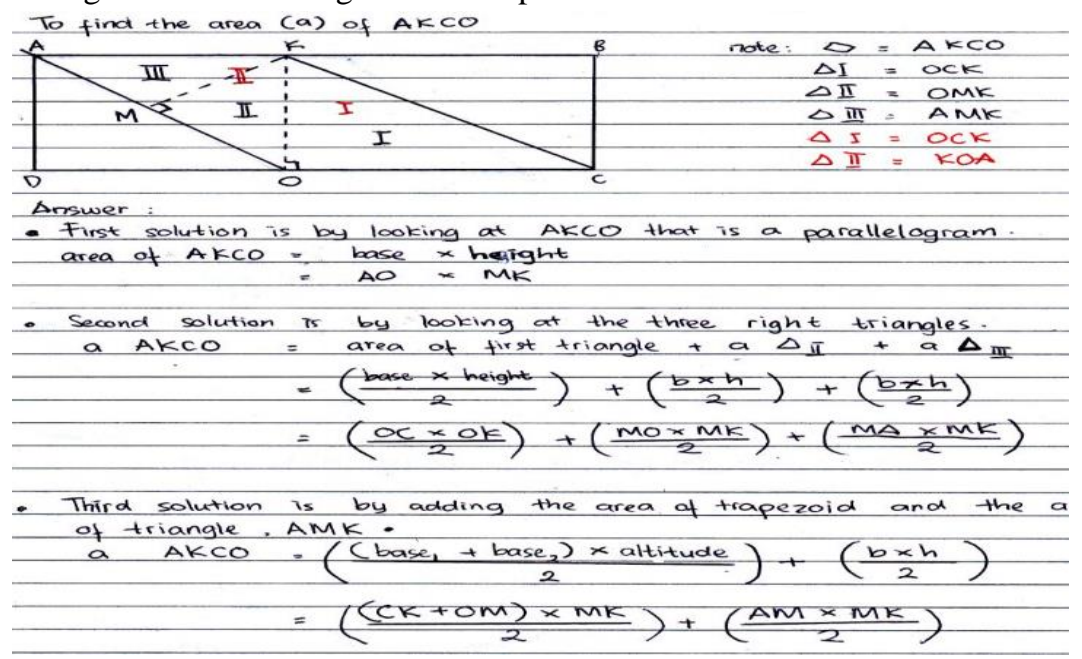

Figure 1 Illustration High Category Answer

Students with medium category also have done the four aspects of thinking. The aspect which is not optimally done students with average category. To give an illustration on the medium category subject's work, the following shows one which has not indicated original answer but only gave one or two solutions and strategies. The result shows that the subject gave 2 alternative answers and both answers are the same as the other subjects. To solve the area in question was done by finding the width of a parallelogram and three of a triangle area. The following is the example.

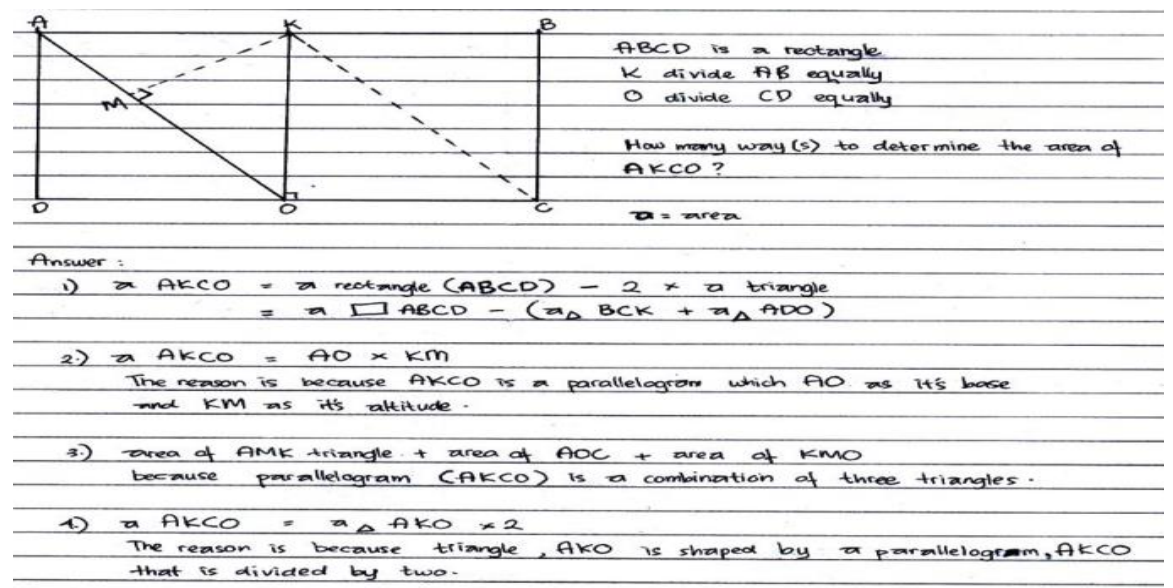

Figure 2 Illustration Medium Category Answer

Students with low category are not yet able to apply the four aspects of mathematical creative thinking and or to give a wrong solution. Based on the answer given, it shows that the subjects gave three solutions. In the first solution, the subject thought that the area in question is the subtraction of the area of a rectangular ABCD with the figure AKCO. Whereas, the problem is the area of the 
geometric figure AKCO; thus, the solution offered is not the correct one. The second solution is one of the correct solutions, considering that the area in question is a combination of two plane figures, so that they would form a parallelogram and its area can be found by calculating the area of a parallelogram, i.e., p x l. However, it does not give a detail in order to arrive at the correct solution. In the third solution, the subject thought that the area in question is the area of a triangle minus the area of a parallelogram. It is not, however, the correct solution.

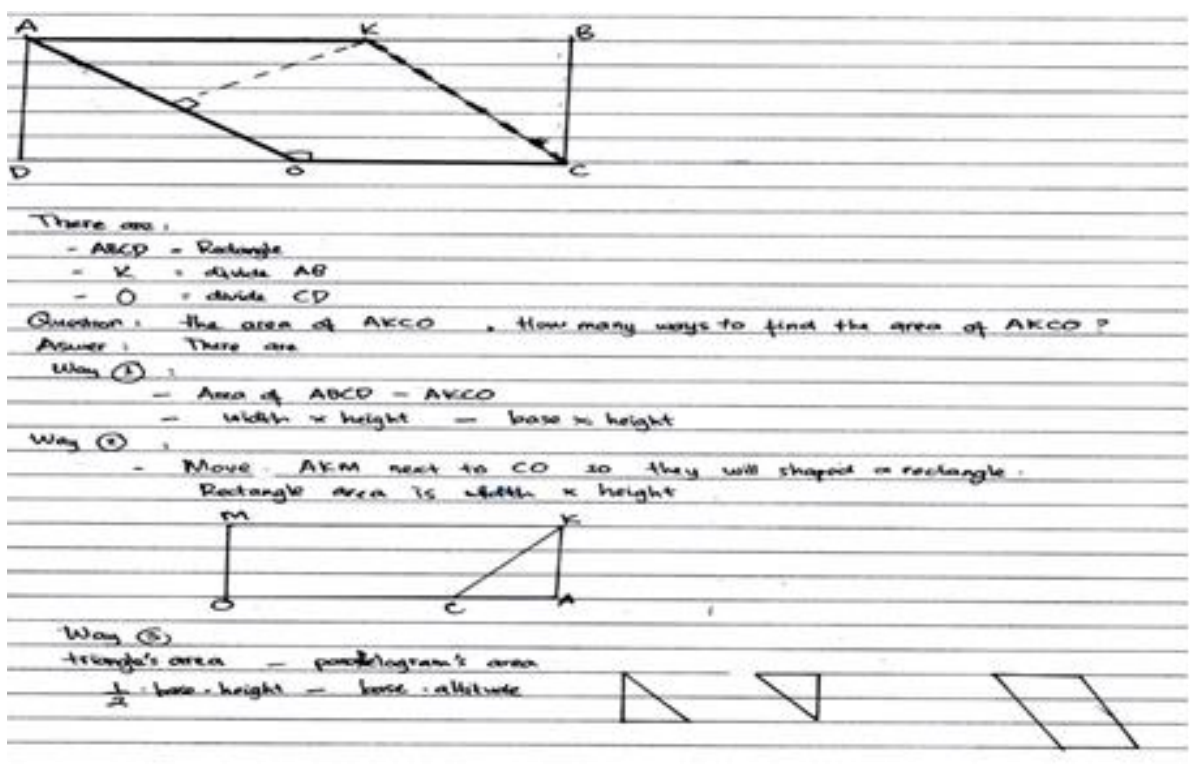

Figure 3 Illustration Low Category Answer

Students in the medium category had also performed four aspects of mathematical creative thinking. Fluency and originality were two aspects that had not mastered yet. Students in the medium category have not shown the originality of the answer and only provide one or two solving strategies. Students with low categories have not been able to apply the four aspects of mathematical creative thinking and or provide an incorrect solution.

The above data are made into a reference to decide future subjects, who are chosen for further detailed interviews. Based on the research need, the subjects who are selected for interviews are those with all educational backgrounds with all categories of learning styles and with low mathematical creative thinking ability. The total subjects chosen in the given data are 6 subjects. The interview topics are related to the problem of the lowness of the mathematical creative thinking ability, especially in the aspect of flexibility, originality, and elaboration all of which are the problem needing for solution.

\section{Summarized of the interviews}




Question 1
Answer (SMA Visual)
Answer (SMA Auditory)
Answer (SMA Kinesthetic)
Answer (SMK Visual)
Answer(SMK Auditory)
Answer (SMK Kinesthetic)
Question 2
Answer (SMA Visual)
Answer (SMA Auditory)
Answer (SMA Kinesthetic)
Answer (SMK Visual)
Answer (SMK Auditory)
Answer (SMK Kinesthetic)
Question 3

Answer (SMA Visual) Answer (SMA Auditory)

Answer (SMA Kinesthetic)

Answer (SMK Visual)

Answer (SMK Auditory)

Answer (SMK Kinesthetic)

Question 4

Answer (SMA Visual)

Answer (SMA Auditory)

Answer (SMA Kinesthetic)

Answer (SMK Visual)

Answer (SMK Auditory)

Answer (SMK Kinesthetic)

Question 5

Answer (SMA Visual)

Answer (SMA Auditory)

Answer (SMA Kinesthetic)

Answer (SMK Visual)

Answer (SMK Auditory)
How many solutions did you find to complete the given problem?

I found three.

Three ways.

Four ways.

There are three, Sir.

There are four ways, Sir.

Four ways, Sir.

Is the solution you offered the correct one?

I don't know, Sir. I think one of them is correct, but don't know how many.

I'm confused, Sir. Because I didn't really understand. Difficult.

I think one of them is correct, Sir. But I'm not sure, because I'm confused.

I don't know, Sir. Maybe one of them is correct, Sir.

Perhaps some are correct, Sir.

I'm sure some are correct, Sir. Although, the long version I don't know.

: Let's look at some correct answers, then, compare with your answer. Is there the same answer and the correct one? (While showing some correct answers of the other subjects.)

It's sure there is no correct answer, Sir. I know now what is wrong.

There is one correct answer, Sir. The second way. Others are wrong. The correct one is the same as the other's way.

There is one correct answer, Sir. But I can't explain the details. The correct one is also the same as the other friends' way.

I'm sure none is correct, Sir. But now I know what is wrong.

Two are correct, Sir. The others are wrong.

Two are correct, Sir. The two others are wrong.

: Based on your correct answers, can you explain detailed steps until the size of the area is found?

I can't, Sir. There's no correct answer, right?

I can, Sir, by using equivalence of the area of the parallelogram, Sir. But I forget the formula, Sir. There are two parallel sides and heights, that's it, Sir. I forget it for sure.

I can, Sir. I'll draw it first, ok? The figures consist of two rectangles which are divided to two. So, I'll find the area of the rectangle first, then divide it into two.

No, Sir. There's no correct answer, Sir.

Viewed from the figure, it looks like a parallelogram, Sir. So, I used the parallelogram formula, base multiplied by height, Sir. But it's hard to find the base, so I can't find the result. This way is not a new way, Sir, the same as the other friends.

: I used the sum of the areas of the triangle and the trapezoid, Sir. But, its height should be found, Sir. And it's hard because I must use Pythagorean formula, Sir. This way is the same as some of my friends' way, Sir.

: What caused you to be unclear about the problem in this form of test?

: I'm from Social Science, Sir, so I can't do mathematics. But I turned out to be able, Sir. But, basically, I can't do it and it makes me dislike learning mathematics.

I don't like mathematics, Sir. I am taking Social Science.

: Don't like mathematics and I am taking Social Science, Sir, so mathematics will not be very difficult.

: I'm not accustomed to the problem, Sir. One answer is usually enough, Sir. I also took SMK because there is not much mathematics, Sir.

: I actually don't like it, Sir. That's why I entered SMK. I am also confused 


\author{
Answer (MA Kinesthetic) : : I can't find any other way, Sir. I have no idea at all. I'm asking Social \\ Science, Sir, so I will not meet mathematics. Don't like it, Sir.
}

The result of the interviews presents a clearer illustration on the subjects with a low ability in mathematical creative thinking, because of a number of factors, such as the lack of ideas in giving solution alternatives, the same solution strategies, and the unfinished and unorganized solution, resulting in no final solution.

\title{
DISCUSSION
}

The results of in-depth interviews of the 6 selected subjects indicate that all subjects do not like mathematics. Five of them say that the dislike happens because the teaching process is not interesting and only work on the book questions. Educators did not motivate the learners in an interesting way. This happened since they were in junior high school. One of the reasons they are majoring in elementary school teacher is to reduce the burden in learning mathematics. They assume that with this department the burden in learning mathematics will be less. Turns out, it was different in classes, not just material but how to teach the material in a way that is good and correct. This is what makes them encountering troubles in learning mathematics so that their mathematical creative thinking ability is still in the low category.

The interview results also provide information that the mathematical creative thinking was low because of the lack of ideas in providing alternative solutions to problem solving. The problem solving strategy is not diverse (similar to other students), and the completion stage is incomplete and unfinished. This result is in line with the opinion of Best \& Thomas (2007); Torrance (1969) and McGregor (2007) who stated that to produce something creative as a result of creative thinking (in this case mathematics) it is required a process that produces something new with a new idea, original idea, to solve problems that exist both well and respectively. If one is unable to think of a solution or not even understanding the given problem then one will not be able to create a solution to the problem let alone be guided by many new ways. Even to get creative thinking especially in mathematics, Vale \& Barbosa (2015) requires a high curiosity with the process of exploration and observation, and imagination and original thinking thing. If someone does not like what is being learned then the thinking process will be hampered, they cannot be demanded to think creatively.

This data is used as a material to start the scaffolding process. The indirect scaffolding process helps them understand and work on mathematics problems but focuses on building their commitment to becoming a teacher. This becomes important because their mood will affect their learning process. After this process is adequate to give understanding and build their commitment then the process of scaffolding done. Deep scaffolding process is only done on 3 selected subjects, 1 subject for each learning style. Three other subjects considered to have been able to resolve the questions well after being guided and be reminded of the formula used, because they have forgotten the formula is the only problem.

The first step in scaffolding is to build the motivation of the subject. The goal is to motivate the subject to have a learning commitment to the topic to be resolved. The subject needs to be motivated and directed about the importance of the topic being studied and the benefits in their later work as pre-service teachers. This is in line with Dennen's (2004) thinking, that scaffolding gives cognitive and emotional influences, not only affecting skills and knowledge, but also motivation and builds the confidence of learners in doing the task. The results of interviews from 6 selected subjects, they have less good experience of mathematics even at the level of junior high school. So, there should be a change in the subject's understanding of mathematics and learning. Thus the subject will have a 
positive attitude towards mathematics so that the scaffolding process runs smoothly and helps the subject solve the given mathematical problem.

The second step is to explain and construct the correct concept and work on the problem. The goal is to provide reinforcement that the information in the matter is not unfamiliar and they can work on it. With this concept, the subject will be able to think from what they have understood, so that they are able to solve problems within their range of ability (Zone of Proximal Development (ZPD)) (Vygotsky, 1978). In the end the three subjects are able to solve the problem with the help given. If this process succeeds then the learning process on the more complex will be successful too (Vygotsky, 1978).

These results indicate that scaffolding helps the subject in solving the problems they face even though each subject takes a different time. The interview results support this result, in which the subject is more likely to understand the content of the question, and be able to think how the solution of the problem in given question. Subjects also said that the provided assistance gave them direction to get a solution they had not previously had. In addition, the explanation and props are used to provide simulation of the problems that exist in the matter so that the subject is able to think of the solution.

The scaffolding process of each subject takes different times according to the subject's ability to receive the help and also depend on their learning styles. The results show that subjects with visual and kinesthetic learning styles are more quickly to understand and solve the problems. Subjects with auditory learning style require a longer scaffolding process. Subjects with auditory learning style require a detailed explanation, the need for media to guide problem solving. This indicates that the scaffolding needs of each subject are different and this must be considered by the scaffolding giver to provide assistance according to the needs of the subject. This is in line with the opinion Vygotsky (1978) that the provision of assistance through scaffolding must be tailored to the needs of the subject. If subjects are able to solve their own problems; then they should be given an independent work to solve so that scaffolding will form an independent person (Williams, 2008) and self-confidence subject (Akhtar, 2014). So the subject that failed or cannot solve the problem in the matter can be helped by scaffolding (Lange, 2002).

The assistance are given to the subject through scaffolding, used in explaining, reviewing and reconstructing subjects' concepts about something so that subjects have a better understanding on the concept and be able to build the concept properly and be able to utilize in everyday life (Ormond, 2016). The technique and duration of the scaffolding process depend on the learning styles and the subject's ability to follow the scaffolding process. A teacher in doing scaffolding must be able to provide correct instructions and carefully according to the needs of the subject (Bikmaz, 2010). If this instruction is correct then it will build and develop the subject's knowledge.

The scaffolding process should be done according to the subject's response and the subject's needs according to their learning styles. Subjects with visual learning style require visual aids to make it easier to understand and solve problems. Subjects with auditory learning style require detailed explanations and props to understand and solve problems. Subjects with kinesthetic learning style require image simulation to provide help in understanding and solving problems. Although they have different learning styles, scaffolding process will be successful when used along with the media, either in the form of props and simulation images. 


\section{CONCLUSION}

The first result of this study indicates that the subjects have different creative thinking abilities seen from his learning style. The lack of the subjects' mathematical creative thinking abilities is due to the lack of love of mathematics. Flexibility and originality are the aspects of creative thinking that are still low. The second result of this study shows that scaffolding according to the subject's learning style can help to improve the ability of mathematical creative thinking. The scaffolding process begins with the provision of motivation, explaining, constructing the correct concept and working on the problem. The technique and duration of the scaffolding process depend on the learning style and the subject's ability to follow the scaffolding process. The speed of the subject in receiving assistance through scaffolding takes different times. Although they have different learning styles, scaffolding process will be successful when used along with the media, either in the form of props and simulation drawings.

\section{Acknowledgements}

We gratefully acknowledge the useful comments of Prof. Dr. Sutarto Wijono, M.A and Dr. Adi Setiawan, M.Si, lecturer in Universitas Kristen Satya Wacana.

\section{Declaration of Conflicting Interest}

The author(s) declared no potential conflicts of interest with respect to the research, authorship, and/or publication of this article.

\section{Funding}

The author(s) disclosed receipt of the following financial support for the research, authorship and/or publication of this article: We gratefully acknowledge research funding from the Universitas Kristen Satya Wacana Salatiga.

\section{REFERENCES}

Akhtar, M. (2014). Patterns of scaffolds in one-to-one mathematics teaching: An analysis. Educational Research International, 3(1), 71-79.

Jelfs*, A., Nathan, R., \& Barrett, C. (2004). Scaffolding students: suggestions on how to equip students with the necessary study skills for studying in a blended learning environment. Journal of Educational Media, 29(2), 85-96.

Best, B., \& Thomas, W. (2007). Everything you need to know about teaching but are too busy to ask: Essential briefings for teachers. Continuum International Publishing Group.

Bire, A., \& Bire, J. (2016). PENGARUH GAYA BELAJAR VISUAL, AUDITORIAL, DAN KINESTETIK TERHADAP PRESTASI BELAJAR SISWA. Jurnal Kependidikan: Penelitian Inovasi Pembelajaran, 44(2). Retrieved from https://journal.uny.ac.id/index.php/jk/article/view/5307

BIKMAZ, F. H., ÇELEB, Ö., Aslıhan, A. T. A., Eren, Ö. Z. E. R., SOYAK, Ö., \& REÇBER, H. (2010). Scaffolding strategies applied by student teachers to teach mathematics. The International Journal of Research in Teacher Education, 1(3), 25-36.

Dennen, V. P., \& Burner, K. J. (2008). The cognitive apprenticeship model in educational practice. Handbook of research on educational communications and technology, 3, 425-439. 
DePorter, B.; Mark, R., \& Sarah, S. (2014). Quantum Teaching. Bandung: PT Mizan Pustaka.

Dyer, J., Gregersen, H., \& Christensen, C. M. (2011). The innovator's DNA: Mastering the five skills of disruptive innovators. Harvard Business Press.

Holton, D., \& Clarke, D. (2006). Scaffolding and metacognition. International journal of mathematical education in science and technology, 37(2), 127-143.

Jelfs*, A., Nathan, R., \& Barrett, C. (2004). Scaffolding students: suggestions on how to equip students with the necessary study skills for studying in a blended learning environment. Journal of Educational Media, 29(2), 85-96.

Lajoie, S. P. (2005). Extending the scaffolding metaphor. Instructional Science, 33(5), 541-557.

Lakkala, M., Muukkonen, H., \& Hakkarainen, K. (2005). Patterns of scaffolding in computer-mediated collaborative inquiry. Mentoring \& Tutoring: Partnership in Learning, 13(2), 281-300.

Lange, V. L. (2002). Instructional scaffolding. Retrieved July 13, 2017 from http://condor.admin.ccny.cuny.edu/ group4/Cano/Cano\%20Paper.doc.

Mann, E. L. (2006). Mathematical creativity and school mathematics: Indicators of mathematical creativity in middle school students (Doctoral dissertation, University of Connecticut).

Mairing, J. P. (2016). Kemampuan Siswa Kelas VIII SMP Dalam Memecahkan Masalah Matematika Berdasarkan Tingkat Akreditasi. Jurnal Kependidikan: Penelitian Inovasi Pembelajaran, 46(2), 179-192.

McGregor, D. (2007). Developing thinking; developing learning. McGraw-Hill Education (UK).

McNeill, K., Lizotte, D., Krajcik, J., \& Marx, R. (2006). Supporting Students' Construction of Scientific Explanations by Fading Scaffolds in Instructional Materials. The Journal of the Learning Sciences, 15(2), 153-191. Retrieved from http://www.jstor.org/stable/25473515

Nathan, M. J., \& Koedinger, K. R. (2000). Teachers' and researchers' beliefs about the development of algebraic reasoning. Journal for Research in Mathematics Education, 168-190.

Nindiasari, H., Novaliyosi, N., \& Subhan, A. Desain Didaktis Tahapan Kemampuan Dan Disposisi Berpikir Reflektif Matematis Berdasarkan Gaya Belajar. Jurnal Kependidikan: Penelitian Inovasi Pembelajaran, 46(2), 219-232.

Ormond, C. A. (2016). Scaffolding the Mathematical" Connections": A New Approach to Preparing Teachers for the Teaching of Lower Secondary Algebra. Australian Journal of Teacher Education, 41(6), 122-164.

Sriwongchai, A. (2015). Developing the mathematics learning management model for improving creative thinking in Thailand. International Education Studies, 8(11), 77.

Sternberg, R. J. (2005). Creativity or creativities?. International Journal of Human-Computer Studies, 63(4), 370-382.

Sternberg, R. J. (2006). The Nature of Creativity. Creativity Research Journal, 18/1, 87-98.

Torrance, E. P. (1995). The 'beyonders' in why fly. A philosophy of creativity. 
Vale, I., \& Barbosa, A. (2015). Mathematics Creativity in Elementary Teacher Training. Journal of the European Teacher Education Network, 10, 101-109.

Vygotsky, L. S. (1980). Mind in society: The development of higher psychological processes. Harvard university press.

Williams, L. (2008). Tiering and Scaffolding: Two Strategies for Providing Access to Important Mathematics. Teaching Children Mathematics, 14(6), 324-330. 